\title{
A systematic approach to the management of massive hemoptysis
}

\author{
Christopher Radchenko ${ }^{1}$, Abdul Hamid Alraiyes ${ }^{2}$, Samira Shojaee ${ }^{3}$ \\ ${ }^{1}$ Department of Pulmonary and Critical Care Medicine, University of Missouri-Kansas City, Kansas City, MO, USA; ${ }^{2}$ Department of Medicine, \\ Rosalind Franklin University, North Chicago, IL, USA; ${ }^{3}$ Departments of Pulmonary Disease and Critical Care Medicine, Virginia Commonwealth \\ University Medical Center, Richmond, Virginia, USA \\ Contributions: (I) Conception and design: S Shojaee; (II) Administrative support: All authors; (III) Provision of study materials or patients: S Shojaee; \\ (IV) Collection and assembly of data: All authors; (V) Data analysis and interpretation: All authors; (VI) Manuscript writing: All authors; (VII) Final \\ approval of manuscript: All authors. \\ Correspondence to: Samira Shojaee, MD, FCCP. Assistant Professor of Medicine; Fellowship Director, Interventional Pulmonology, Pulmonary Disease \\ and Critical Care Medicine, Virginia Commonwealth University, PO Box 980050, Richmond, VA 23298, USA. Email: sshojaee@mcrh-vcu.edu.
}

\begin{abstract}
Massive hemoptysis is regarded as a potentially lethal condition that requires immediate attention, and prompt action. Although minor hemoptysis is frequently encountered by most clinicians, massive hemoptysis in far less frequent and most physicians are not prepared to manage this time-sensitive clinical presentation in a systematic and timely fashion. Critical initial steps in management need to be implemented in an expedited fashion, such that patients may have a chance at a more definitive treatment. In this article, we review the definition, vascular anatomy, etiology, diagnostic evaluation, epidemiology and prognostic markers of massive hemoptysis. A systematic approach to management, stabilization and treatment options is followed. An algorithm is proposed for the management of massive hemoptysis and the importance of a multidisciplinary approach is emphasized.
\end{abstract}

Keywords: Massive hemoptysis; life-threatening hemoptysis; systematic approach

Submitted May 02, 2017. Accepted for publication May 19, 2017.

doi: $10.21037 /$ jtd.2017.06.41

View this article at: http://dx.doi.org/10.21037/jtd.2017.06.41

\section{History}

Massive hemoptysis had been long recognized by physicians as an emergent and incurable presentation, and it wasn't until the late 1940's, whereby surgical treatment which had an impact on clinical outcome, was described. This treatment was aggressive as the nature of massive hemoptysis was deemed to be that of a surgical emergency. It was stressed that after localizing the bleeding site, massive hemoptysis constituted a clear indication for thoracotomy (1-3).

Management principles focused on patient examination, positioning for postural drainage, minimization of sedatives to ensure preservation of the cough reflex, and blood transfusion initiation. Pituitary derivatives as well as conjugated estrogens were used to aid in cessation of bleeding (4). Rigid bronchoscopy was performed in the operating room, only as a prelude to thoracotomy. Over time, other approaches such as insertion of bronchial blockers, packing of the affected bronchial orifice with cotton swabs and single lung ventilation by way of mainstem intubation were performed. The operative procedure depended on the findings, where ultimately lung resections, to different extents were performed.

The prognosis of patients presenting with massive hemoptysis was primarily derived by the degree of hemorrhage, and subjects' surgical candidacy.

As technology and innovation advanced, as well as our understanding of the pathophysiology, reassessment of the previously described surgical approaches commenced. With improved availability of flexible bronchoscopy, the advent of computed tomography (CT) scanning, as well as the introduction of angiography with subsequent bronchial artery embolization (BAE) (5), the optimal treatment strategy was redefined. 


\section{Epidemiology and natural history}

One difficulty in determining the epidemiology of massive hemoptysis is that there is no universally accepted definition (see definition below). Although hemoptysis is a more common clinical finding reportedly responsible for $6.8 \%$ of outpatient pulmonary clinic visits, $11 \%$ of admissions to a hospital pulmonary service, and $38 \%$ of patients referred to a thoracic surgery practice $(6,7)$, massive hemoptysis is relatively rare. Studies estimate that $4.8-14 \%$ of patients presenting with hemoptysis will have massive hemoptysis (8-13), however this is debated given the heterogeneity of studied populations. Tuberculosis, bronchiectasis, lung abscesses and mycetomas have been consistently reported as common causes of massive hemoptysis (6). Up to $20 \%$ of lung cancer patients will experience hemoptysis at some point in their clinical course, but massive hemoptysis affects only $3 \%$ of this population (14). Massive hemoptysis in cystic fibrosis is reported to have an annual incidence of $0.9-4.1 \%(15)$.

Despite differences in the criteria used to define massive hemoptysis, risk of death from hemoptysis has correlated with the rate of bleeding. An early study reported mortality rates exceeding $70 \%$ in patients with bleeding rates greater than $600 \mathrm{~mL}$ in 4 hours (hr). Furthermore, prior to the widespread use of BAE, those deemed inoperable had mortality rates greater than $75 \%$ when bleeding greater than $600 \mathrm{~mL}$ within $16 \mathrm{hr}(9)$.

As improved diagnostic and therapeutic modalities developed, reported mortality rates have decreased with recent studies quoting mortality rates ranging from $6.5-38 \%$ (11,16-20).

\section{Definition}

Massive hemoptysis is a term used to describe a large amount of expectorated blood or rapid rate of bleeding, giving the impression that it, in and of itself, is associated with a serious risk of mortality. Although regarded as a potentially lethal condition, there is no clear consensus on its definition. As this clinical phenomenon has been described over the years, no uniform volume of hemoptysis has been agreed upon in the literature (6). Thresholds ranging from $100 \mathrm{~mL} / 24 \mathrm{hr}$ to more than $1,000 \mathrm{~mL} / 24 \mathrm{hr}$ have been proposed to define massive hemoptysis (8-11,16,21-23). Additionally, other terms such as "major" hemoptysis, "severe" hemoptysis, and "exsanguinating" hemoptysis have been used to describe the various degrees of bleeding. Finally, "life-threatening" hemoptysis has been employed as a definition; understanding that there is no uniform volume that may assign a predictable risk of mortality, to a vastly divergent patient population $(17,23)$.

In practice, the quantification of hemoptysis is often difficult, and in many cases can be under-reported or exaggerated by patients. This realization has further led to the use of the "magnitude of effect" definition of massive hemoptysis. Morbidity and mortality in patients with hemoptysis depend on not only the volume of expectorated blood, but the rate of bleeding, the timeliness of hemoptysis management and the extent and severity of any underlying disease reducing one's cardiopulmonary reserve.

Massive hemoptysis magnitude of effect is defined as the volume of expectorated blood that is life-threatening by virtue of airway obstruction, hypotension or blood loss (15,23-25). This definition relies on the main clinical consequence of hemoptysis; examples of such a definition have included hemoptysis requiring transfusion, hospitalization, intubation, aspiration of blood to the contralateral lung, airway obstruction, hypoxemia requiring mechanical ventilation $\left(\mathrm{PaO}_{2}<60 \mathrm{mmHg}\right)$ and death $(6,15,18,24-26)$.

\section{Vascular anatomy}

Two vascular circulations, the pulmonary and the bronchial systems supply the lungs. The former functions to perform oxygenation and carbon dioxide excretion from the body, while the latter provides arterial blood to the tracheobronchial tree, as well as other structures to the level of the terminal bronchioles. They also provide blood flow to hilar lymph nodes, visceral pleura, pulmonary arteries and veins, vagus nerve, and esophagus. The pulmonary arterial system, which is a low-pressure circuit (normal pressures of $15-20 \mathrm{mmHg}$ systolic and $5-10 \mathrm{mmHg}$ diastolic), carries blood from the right ventricle across the highly vascular pulmonary capillary bed and return it via the pulmonary veins to the left atrium. The pulmonary arteries interact with the airway only at the level of the terminal bronchiole, where they branch extensively around the alveoli for efficient gas exchange $(27,28)$.

Massive hemoptysis usually arises from the highpressure bronchial circulation (90\%). In approximately 5\% of the cases, it arises from the aorta (ruptured aneurysms, aortobronchial fistulae), or non-bronchial systemic circulation (intercostal arteries, coronary arteries, thoracic arteries originating from the axillary and subclavian arteries, 
and the upper and inferior phrenic arteries) and in another $5 \%$, massive hemoptysis may arise from the pulmonary vessels (29-31).

Bronchial arteries arise either directly or indirectly from the aorta at the level of the third through eighth thoracic vertebrae, most frequently at T5-T6 (32). At least ten different patterns of bronchial arteriolar anatomy have been recognized. The most common patterns that have been described are a single intercostal trunk on the right from which the right bronchial arteries arise and a single left bronchial artery (30.5\%); an intercostal trunk on the right giving rise to the right bronchial artery and a second common trunk form which right and left bronchial arteries arise (25\%); a right intercostal trunk giving rise to a bronchial artery and two bronchial arteries on the left $(12.5 \%)$ (33). About $20 \%$ of bronchial arteries have an aberrant origin from other systemic non-bronchial arteries. In $5 \%$ of patients, a spinal artery originates from the bronchial artery (34).

Anastomoses between the bronchial arteries and tributaries of the pulmonary veins have demonstrated in normal lungs at postmortem (28); these anastomoses permit drainage of bronchial arterial blood into the left heart. During chronic inflammatory or infectious lung conditions, the volume of such communications may increase. Enlargement and marked tortuosity of bronchial arteries, and increased arterial blood flow have been observed. In these circumstances, new collaterals from the bronchial arteries or from other intrathoracic systemic arteries may develop. These pathological changes can account for an increased risk of bleeding (28).

\section{Etiologies}

Etiologies of massive hemoptysis and their record in the literature have evolved over time. While prevalence of tuberculosis (TB) has declined in developed countries, with improved medical care of chronic lung diseases, the incidence and ultimately prevalence of bronchiectasis has increased $(35,36)$.

Through the 1960's, three etiologies accounted for $90 \%$ of the cases of massive hemoptysis: TB, bronchiectasis, and lung abscess (27). With advancing technology and the more frequent use of CT scanning, both etiology and pathophysiology of massive hemoptysis is better described.

Bronchiectasis, TB, mycetomas, necrotizing pneumonia, cryptogenic hemoptysis and bronchogenic carcinomas are considered among the most common causes of massive hemoptysis (Table 1). Although TB accounts for fewer cases of massive hemoptysis in recent literature, it remains the most common cause of massive hemoptysis worldwide with high prevalence of the disease in Africa and China $(11,16,18,37,47)$. In a retrospective cohort study, conducted over a 14-year period at a tertiary university hospital in Paris, France, investigators showed that of 1,087 patients, bronchiectasis (20\%), cryptogenic (18\%), cancer (17\%), active TB (12\%), and sequelae of TB (13\%) were the most common causes of massive hemoptysis in that patient population. The average cumulative volume of hemoptysis in these patients was $218 \mathrm{~mL}$ (19).

In bronchiectasis, chronic airway inflammation causes hypertrophy and tortuosity of the bronchial arteries that accompany the regional bronchial trees, as well as expansion of the submucosal and peribronchial plexus of blood vessels. Rupture of either the tortuous vessels or the capillary plexus results in rapid bleeding subject to systemic blood pressure in these vessels. Bronchiectasis may result from prior infection (bacterial, viral, TB), cystic fibrosis, host immune defects or impairment of the mucociliary clearance apparatus such as in ciliary dyskinesia seen in Kartagener's or Young's syndromes.

Massive hemoptysis can be a consequence of either active or prior TB. In active TB, massive hemoptysis can occur in cavitary or non-cavitary disease. This usually results from bronchiolar ulceration with necrosis of adjacent blood vessels (27). Bleeding is usually from the bronchial arterial circulation, but occasionally active TB may cause rupture of a Rasmussen's aneurysm, which is derived from the pulmonary arterial circulation (48). In prior $\mathrm{TB}$, causes of massive hemoptysis are usually a consequence of either erosion of a calcified lymph node (bronchiolite) through a bronchial artery and into an airway, bronchiectasis secondary to structural damage from prior $\mathrm{TB}$, or mycetoma formation in a lung cavity from prior infection with TB (49).

Approximately $20 \%$ of patients with lung cancer will experience hemoptysis at some point during their course, but only $3 \%$ of patients will present with massive hemoptysis (50). The presence of large, centrally located tumors with cavitation and especially squamous cell carcinoma is associated with massive hemoptysis. $\mathrm{Up}$ to $80 \%$ of patients with massive hemoptysis due to malignancy have history of small sentinel bleeding episodes during the prior weeks.

Despite advances and innovations in medicine, there still remain up to $20 \%$ of cases where no overt cause can 
Table 1 Underlying etiology of massive hemoptysis in previous studies

\begin{tabular}{|c|c|c|c|c|c|c|c|c|c|}
\hline Study & Country & Patients (n) & \multicolumn{7}{|c|}{ Underlying cause of hemoptysis (\%) } \\
\hline Fartoukh et al. (19) [2012] & France & 1087 & 20 & 25 & 17 & 6 & - & 18 & 20 \\
\hline Shigemura et al. (37) [2009] & China & 62 & 23 & 55 & 6 & 8 & 6 & - & 2 \\
\hline Ong and Eng (18) [2003] & Singapore & 29 & 66 & 10 & 7 & 14 & - & - & 3 \\
\hline Hsiao et al. (40) [2001] & USA & 28 & 57 & 7 & 14 & - & - & 7 & 14 \\
\hline Revel et al. (41) [2002] & France & 80 & 31 & 19 & 11 & 7.5 & - & 10 & 21.5 \\
\hline $\begin{array}{l}\text { Gourin and Garzon (42) } \\
\text { [1974] }\end{array}$ & USA & 62 & 11 & 73 & 3.2 & - & 6.5 & - & - \\
\hline McCollum et al. (43) [1975] & USA & 15 & 20 & 33 & 6.7 & 13.3 & - & 6.7 & - \\
\hline Yang and Berger (44) [1978] & USA & 20 & 15 & 50 & 15 & 5 & - & 10 & - \\
\hline Garzon et al. (25) [1982] & USA & 24 & 17 & 46 & 13 & - & 8 & 8 & - \\
\hline Conlan et al. (45) [1983] & South Africa & 123 & 30 & 38 & 4.9 & 3.3 & 4.9 & - & - \\
\hline Uflacker et al. (33) [1985] & Brazil & 75 & 1.3 & 76 & - & 16 & 2.6 & - & - \\
\hline
\end{tabular}

be discerned, and thus categorized as cryptogenic massive hemoptysis $(17,19)$. Cryptogenic massive hemoptysis is more likely to develop in smokers $(51,52)$.

Fungal infections have increased in frequency, especially among patients who are immunocompromised, or have preexisting cavitary lung disease. Among fungal infections, aspergilloma is the most common cause of massive hemoptysis with rates from 50-90\% (27). Invasive pulmonary parenchymal fungal infections can cause massive hemoptysis, particularly in aspergillus or mucor infections (27). This is due to the distortion of parenchymal and vascular structures, ultimately inducing massive hemorrhage.

The prevalence and etiologies of massive hemoptysis, as reported in previous studies, are summarized in Table 1. A comprehensive list of causes is represented in Table 2.

\section{Diagnosis}

The diagnostic workup for massive hemoptysis should be undertaken as soon as possible and after the patient has been stabilized. A thorough evaluation should begin with a history and physical examination when possible; this not only can provide insight into a possible etiology, but may also aid in determining the most appropriate next step in management. Examination should focus on ruling out non-pulmonary causes of bleeding such as epistaxis or hematemesis. 
Table 2 Causes of massive hemoptysis

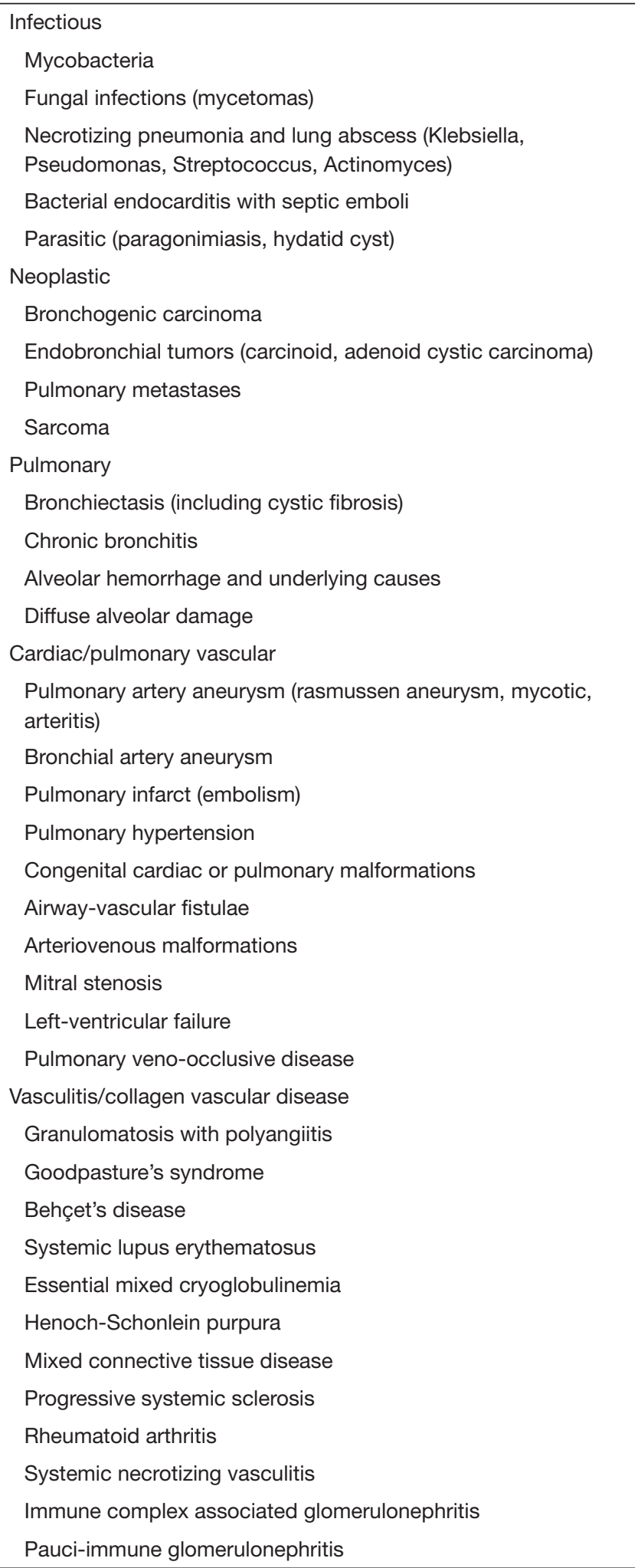

Table 2 (continued)
Table 2 (continued)

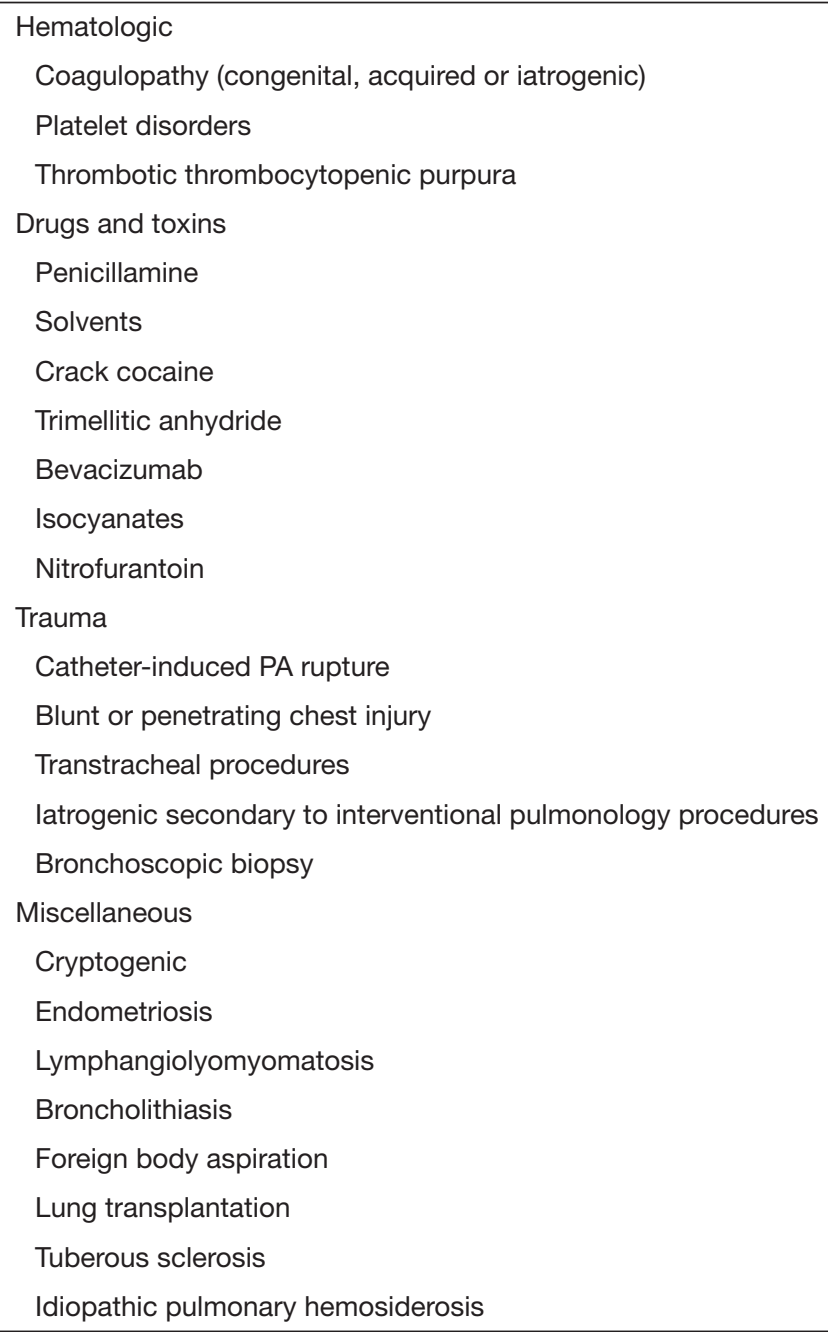

PA, pulmonary artery.

Primary laboratory studies should be sent and include type and cross-matching of blood, complete blood counts and differential, coagulation profile, electrolytes, liver function tests, urinalysis, and arterial blood gas.

The utility of fiberoptic bronchoscopy (FOB) in localizing the bleeding site in the setting of minor hemoptysis is significantly lower when compared to massive hemoptysis. In the setting of massive hemoptysis, FOB is the initial diagnostic procedure of choice in patients with massive hemoptysis because it can be performed at the bedside, it is readily available, and it is often successful at localizing the bleeding site if it is performed while the patient is bleeding $(27,31)$. Reviewing patients in a retrospective study, Hsiao et al. showed that FOB 
successfully localized the bleeding site in $93 \%$ of patients with massive hemoptysis (40). FOB not only proves to be instrumental in establishing and maintaining a patent airway thus stabilizing the patient, but also provides vital information upon which the next step in management can be taken. Rigid bronchoscopy can be used concomitantly with FOB, as mentioned below.

The imaging modalities pertinent to the evaluation of massive hemoptysis include chest radiography (CR), multidetector CT scan and thoracic aortography-BAE. There is uniform recognition of the efficacy of CR in the initial evaluation, as it can be performed rapidly and can guide therapy with moderate effect. The reported efficacy of CR in identifying the site of bleeding is based on a wide range of reports (33-82\%), in variable patients populations, during different eras of medicine, in different parts of the world where the epidemiology of disease differed $(11,18,26,40,41,53)$. CR revealed the underlying cause in $35 \%$ of cases (53). Rarely, CRs can be normal, at a rate of $13 \%$ of patients, of whom $70 \%$ had bronchiectasis (41).

CT may be comparable to bronchoscopy for identifying the site of bleeding ( $70 \%$ vs. $73 \%$ respectively), however CT has been found to be more efficient than bronchoscopy in identifying the cause of bleeding $(77 \%$ vs. $8 \%$, respectively, $\mathrm{P}<0.001)$ (41). Several studies compare CT with bronchoscopy, and it has been demonstrated that in a study of 40 cases of hemoptysis with normal bronchoscopy, abnormalities were seen in $50 \%$ of patients on subsequent chest $\mathrm{CT}$ scan. These abnormalities included bronchiectasis (18\%), mass (10\%), alveolar consolidation (10\%), and abnormal vessels (7.5\%) (54). Furthermore, a prospective study compared CT to bronchoscopy in 91 patients with hemoptysis; CT demonstrated all 27 tumors identified at bronchoscopy, as well as seven additional lesions. There were 14 cases of bronchiectasis, all of which were detected by CT alone (55). In $40 \%$ of cases involving positive CRs, CT was complementary to bronchoscopy for clarifying radiographic abnormalities and/or providing new diagnostic information (56). Some suggest that CT can replace bronchoscopy as a first-line investigational approach in a patient with massive hemoptysis because of its higher diagnostic yield (26), while others advocate it as complementary to FOB for bleeding site identification (41). In patients not requiring $\mathrm{FOB}$ for airway management, $\mathrm{CR}$ and $\mathrm{CT}$ are highly informative to guide the approach to BAE (40). In the setting of true massive and life threatening hemoptysis however, FOB is the first-line in management. While CT scanning may not be readily available in an unstable rapidly hemorrhaging patient who will need stabilization prior to transport, bronchoscopy is invaluable. Additionally, although CT scanning has limited benefit in localization of bleeding site in the setting of bilateral lung disease, FOB has proven to be efficient in identifying the site of hemorrhage (31) (Figure 1).

Once airway stabilization and site localization is accomplished, CT scanning of the chest can add additional information with regards to the underlying etiology, which could be easily missed on bronchoscopy, such as bronchiectasis or aspergilloma. One particular benefit in utilizing CT in patients with massive hemoptysis is its ability to precisely delineate bronchial and non-bronchial systemic arterial blood supply. In patients who ultimately undergo BAE, CT prior to this therapy can provide additional information about vascular anatomy (57-59) (see Table 3 for summary).

There has been limited investigation into the role of nuclear imaging in the assessment of massive hemoptysis. However, nuclear imaging may prove limited without the presence of active bleeding, and furthermore, the feasibility of transferring a patient with massive hemoptysis to undergo such study may not be viable.

\section{Prognostic indicators}

Prognostic features for poor outcomes in patients with massive hemoptysis have been identified in the literature. Crocco et al. found a direct correlation between the rate of hemoptysis and mortality, reporting a $71 \%$ mortality rate in patients who lost more than $600 \mathrm{~mL}$ of blood in 4 hours, $22 \%$ mortality rate in patients bleeding greater than $600 \mathrm{~mL}$ within 4 to 16 hours, and a $5 \%$ rate in those with $600 \mathrm{~mL}$ of hemoptysis within 16 to 48 hours (9). Furthermore, patients with bleeding rates exceeding $1,000 \mathrm{~mL} / 24$ hours were shown to have higher mortality reported as $58 \%$ and $78 \%$ in-hospital mortality in previous surgical series $(8,10)$. Other features associated with death include radiographic evidence of aspiration to contralateral lung, hemodynamic instability, massive hemoptysis caused by neoplasm as well as clinical features that would exclude patients from surgical intervention (for example, inadequate pulmonary function, debilitated states, bilateral bleeding sources, inability to localize bleeding, or metastatic cancer) $(7,8,10)$. Aspiration of blood in the contralateral lung, and massive bleeding requiring single-lung ventilation were further associated with higher mortality $(6,8,10)$. Corey and $\mathrm{Hla}$ found that hypotension was associated with increased mortality $33 \%$ 

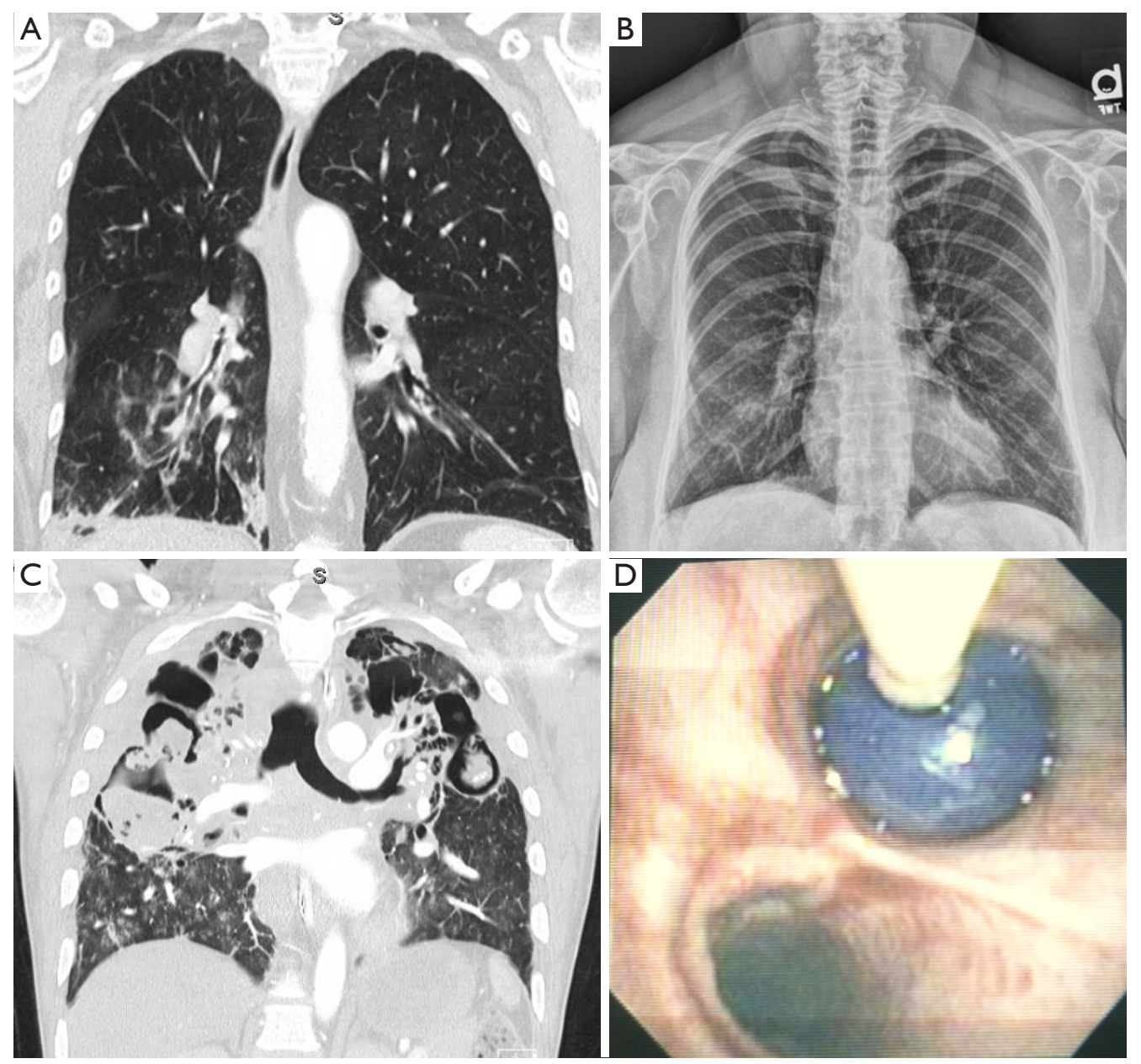

Figure 1 Examples of bronchoscopy requirement for lateralizing. (A,B) A 59-year-old female with massive hemoptysis and evidence of bilateral bronchiectasis. Bronchoscopy revealed right lower lobe as a source of hemorrhage; (C) a 47-year-old male with bilateral cavitation and mycetoma. Right upper lobe was identified as source of bleeding by FOB; (D) both subjects were stabilized by ETT intubation and right sided bronchial blockade prior to BAE. ETT, endotracheal tube; BAE, bronchial artery embolization.

Table 3 Diagnostic tools in evaluation of massive hemoptysis

\begin{tabular}{lclc}
\hline Diagnostic tool & CR (\%) & CT (\%) & FOB (\%) \\
\hline Identifying site of bleeding & $33-82$ & $70-88.5$ & $73-93$ \\
Revealing underlying cause & 35 & $60-77$ & $2.5-8$ \\
\hline
\end{tabular}

$\mathrm{CR}$, chest radiography; CT, computed tomography; FOB, fiberoptic bronchoscopy.

vs. $12 \%)$, requiring blood transfusion had an increased mortality compared to those who did not ( $72 \%$ vs. $27 \%)$, and if patients were considered operable based on clinical/ functional assessments, they had a higher survival rate than those deemed inoperable (8). Although bronchiectasis was found to have a low mortality rate, Osaki et al. found that bronchiectasis was associated with a higher rate of recurrence of hemoptysis in a series of patients treated by BAE (60). Additionally, Van den Heuvel et al. found that in patients who had undergone BAE for life threatening hemoptysis and experienced recurrent bleeding such as in those with bronchiectasis, there was a higher mortality rate. They also identified the following risks for recurrence of hemoptysis: residual bleeding beyond the first week after BAE, blood transfusion before the procedure, and diagnosis of aspergilloma as the underlying etiology. Conversely, patients with active TB undergoing medical treatment experienced significantly fewer episodes of recurrent bleeding events (61). 
In a retrospective study of 30 oncology patients undergoing BAE for varying degrees of hemoptysis, Wang et al found that non-tumor related hemoptysis was associated with better survival in comparison with tumor related bleeding. Of the nine patients who died within 30 days of BAE, eight of them had tumor related hemoptysis (62). Razazi et al. further sought to identify risk factors, which were associated with mortality using univariate and multivariate regression, specifically in patients diagnosed with non-small cell lung carcinoma (NSCLC), who presented with severe hemoptysis (>100 $\mathrm{mL}$ at admission). Retrospectively reviewing 125 patients, the investigators found that preadmission Eastern Cooperative Oncology Group (ECOG) performance status $\geq 2$, advanced stage and mechanical ventilation were independent predictors of inhospital mortality. ECOG performance status $\geq 2$, advanced stage, cancer progression, and cavitation/necrosis were independently associated with 1 -year mortality (63).

Fartoukh et al. retrospectively studied 1,087 patients with hemoptysis at a tertiary hospital, with a mean cumulative expectorated volume of $218 \mathrm{~mL}$. Multivariate logistic regression model showed good concordance between predicted and observed probabilities of death with good discrimination (receiver operating characteristic curve area 0.87; 95\% CI, 0.82-0.92). The model-based score [chronic alcoholism, pulmonary artery (PA) involvement, and radiographic patterns, one point each; cancer, aspergillosis and mechanical ventilation, two points each] predicted the probability of death as follows: score $0,1 \%$; score $1,2 \%$; score 2, 6\%; score 3, $16 \%$; score 4, $34 \%$; score 5, 58\%; score $6,79 \%$, and score 7, 91\% (19). A threshold value of $300 \mathrm{~mL}$ of expectorated blood was the best predictor of in-hospital mortality in univariate analysis. However, after adjusting for other predictors, the estimated volume expectorated did not remain predictive of death.

\section{Initial approach and stabilization}

The initial step in the management of massive hemoptysis should focus on efficient stabilization (64). Advanced cardiac life support (ACLS) should be implemented as soon as possible. The non-bleeding lung should be protected, and this may be achieved by turning the patient to the bleeding side, such that the blood is isolated to the bleeding lung due to gravity, and the non-bleeding side remains intact and fully aerated (65). Ideally, every measure taken to stabilize the airway needs to be calculated, rehearsed in advance and practiced in simulation sessions as a team.
The most important point to note when managing massive hemoptysis, is that time is of the essence and every second lost, may equal to a number of alveoli flooded with blood.

Additionally, it is important to note that massive hemoptysis is often the result of procedural complications. This important fact highlights the value of pre-procedural preparedness and prevention. A review of patients' medications and laboratory studies needs to be undertaken. Coagulation parameters should be evaluated such that appropriate reversal may be employed depending on the clinical scenario. Thrombocytopenia in itself can increase bleeding rates for which previous literature has suggested safety thresholds of $20,000-50,000 / \mathrm{mm}^{3}$ for flexible bronchoscopy, and greater than $50,000 / \mathrm{mm}^{3}$ for transbronchial lung biopsy (TBLB) (66-69). Uremic patients have higher bleeding rates if undergoing invasive procedures such as major surgery, renal biopsy, or TBLB. Dransfield and Garver were able to reduce bleeding risk in lung transplant patients who underwent TBLB by implementing a standardized bronchoscopy guideline, for which patients with a BUN greater than $30 \mathrm{mg} / \mathrm{dL}$ were administered desmopressin prior to their procedure (70).

Antiplatelet medications have been shown to increase bleeding complication rates in patients undergoing TBLB. Although Herth et al. did not show a significant difference in the incidence of minor, moderate or major bleeding in patients taking aspirin (71), the same cannot be said regarding patients taking other antiplatelet regimens. In a study comparing TBLB in patients taking clopidogrel with and without aspirin, Ernst et al. showed alarming rates of mild, moderate and severe bleeding rates in patients taking clopidogrel $(16 / 18,89 \%)$, as well as in those taking clopidogrel plus aspirin (12/12, 100\%) (72). There is insufficient data on newer antiplatelet agents (i.e., prasugrel, ticagrelor) to summarize their effects in patients experiencing hemoptysis, however one must be cognizant of their potential for higher bleeding rates.

\section{Establishing an airway}

Establishing a definitive airway is the most important step in the management of massive hemoptysis $(64,73)$. Multiple modalities have been described to achieve airway control in such settings. The advantages and disadvantages of single lumen endotracheal tube (ETT), double lumen endotracheal tube (DLETT) and rigid bronchoscope are described in Table 4.

Important considerations in securing the airway during 


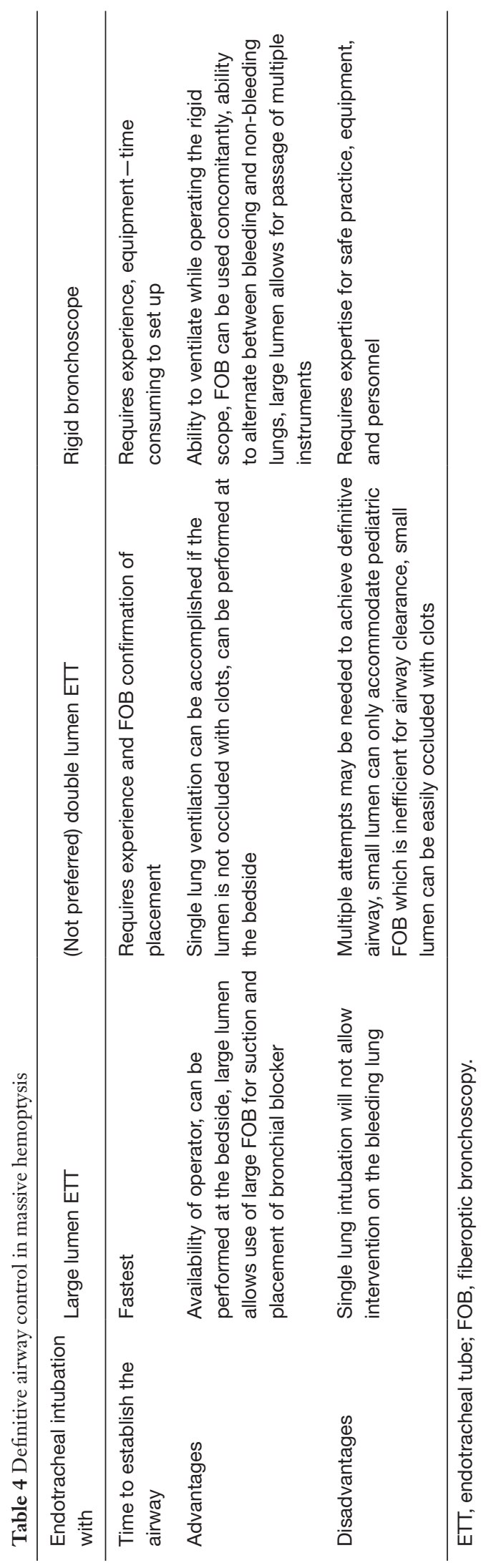

hemoptysis are access to equipment, availability of skilled operators, and an efficient and organized approach to securing the airway. Of the available options to secure the airway in massive hemoptysis, ETT intubation is the most readily available. An ETT with an internal diameter (ID) of $8.5 \mathrm{~mm}$ and above is ideal and necessary in appropriate management. Large lumen (8.5-9 mm ID) ETT allows for the use of instruments such as therapeutic flexible bronchoscope and bronchial blockers without occluding the lumen and limiting ventilation and oxygenation. This is particularly important when managing massive hemoptysis. Clot extraction and recovery of airway patency can be accomplished using therapeutic bronchoscopes with larger working channels. This task is often difficult to accomplish when working through an ETT lumen of less than $8 \mathrm{~mm}$ ID. Once the vocal cords are intubated, the ETT should be advanced beyond the distal trachea, intubating the non-bleeding airway. A flexible bronchoscope should always be used to aid in guiding the ETT or used immediately to verify that the correct mainstem bronchus is intubated. After suction and clearing of the nonbleeding lung from any spilled blood/clots and recovery of oxygenation and ventilation, the next steps can be performed as outlined below. DLETT can provide single lung ventilation and isolation of the bleeding side. However it requires placement by an expert team and even during a controlled nonemergency situation is time consuming. DLETT contains two small working channels, which can accommodate a pediatric size bronchoscope, which is not an effective tool for clot extraction. Most importantly, the small lumens of a DLETT can easily obstruct with blood and clots, making any access to the airway nearly impossible $(23,74)$. We recommend against the use of DLETT in the management of massive hemoptysis (Figure 2).

\section{Bronchoscopy}

While the management of massive hemoptysis has often been described in a stepwise approach, in real life, multiple interventions occur simultaneously. As mentioned above, the primary approach to massive hemoptysis starts with securing an airway, positioning the patient with the bleeding side down, and intubating the non-bleeding airway with a single lumen ETT. It is however, important to notice that in the majority of circumstances, these steps cannot be successfully accomplished without direct visualization using a FOB. If the side of bleeding is known by way of recent history, imaging clues, or immediate pre/post- 


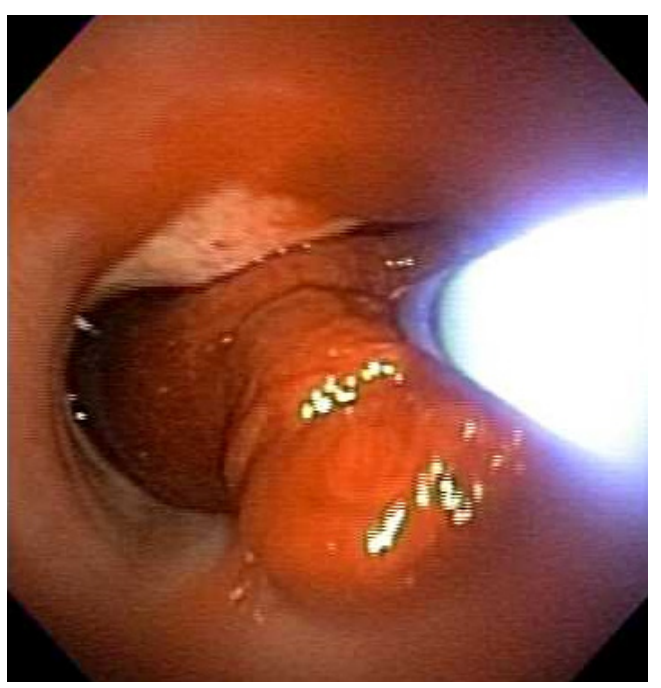

Figure 2 Clot extraction should be efficiently performed through the lumen of a rigid bronchoscope or an ETT with ID of $\geq 8.5 \mathrm{~mm}$. Figure shows a large saddle clot extracted through the lumen of an endotracheal tube with $8.5 \mathrm{~mm}$ ID. ETT, endotracheal tube.

procedure complication, then patient positioning can be successfully accomplished without direct visualization. On many occasions however, FOB is required to localize the side of bleeding. The two key objectives of bronchoscopic management of hemoptysis are: (I) clearing the airway of blood to maintain adequate ventilation (this is especially true in the non-bleeding lung); and (II) establishing a clear vision of the bleeding side to enable implementation of bronchial blocker or other endobronchial techniques (6). As mentioned above, the utility of early FOB in localizing the bleeding side is important in the setting of massive hemoptysis, when compared to mild and moderate hemoptysis (75-77). Hirshberg et al. noted that bronchoscopy was more effective in localizing the bleeding site in the setting of moderate to severe hemoptysis (64\% and $67 \%$ ) versus mild hemoptysis (49\%) (11). Additionally, FOB is often required for successful intubation of the nonbleeding main bronchus. When massive hemoptysis follows an endobronchial procedure such as TBLB, the flexible bronchoscope can be wedged in to the bleeding secondary bronchus to tamponade and stop the spillage of blood to the surrounding bronchi and the non-bleeding lung. This can be accomplished while the patient is placed with the bleeding lung in dependent position. In such circumstances, it is recommended to avoid use of suction and allow for clot formation and tamponade, all while the bronchoscope is wedged in place for at least $3-5$ minutes $(6,76,78-80)$.

\section{Bronchial blocking techniques}

The bleeding site should be isolated and blocked for two reasons; first, bronchial blockade prevents the aspiration and contamination of blood in the contralateral lung, which allows for continued ventilation to the unaffected side. Second, stabilization provides sufficient time for the next step in management, often requiring patient transport for interventional radiology or surgical management. Additionally, on occasion, bronchial blockade can result in tamponade, clot formation and temporary hemostasis (80).

A bronchial blocker, occasionally used during surgical procedures requiring single lung ventilation, can be used to isolate the bleeding lobe or lung, while providing ventilation to the remainder of the lung. In one of the first demonstrations of bronchial blockade therapy for massive hemoptysis, a silicone spigot was advanced with bronchoscopic guidance to the right upper lobe, and left in place for a successful BAE which followed 2 hours later (81). Several commercially available bronchial blockers such as Arndt blocker, Cohen Flexitip blocker, Fuji Uniblocker, and the EZ Blocker may be used (82). A bronchial blocker consists of a long flexible catheter $(4.5 \mathrm{~F}-$ 9F, 65-78 cm length) that is inserted through the ETT, usually with bronchoscopic guidance to the bleeding airway. The distal end of the catheter contains a cuff that can be inflated in the mainstem or lobar branches. Since bronchial blockers are prone to dislodgement, they are usually placed in the mainstem bronchi or the bronchus intermedius. An adapter at the proximal end of the ETT allows separate ports for entry of the blocker, bronchoscope and attachment of ventilator tubing simultaneously (83). The use of a bronchial blocker is a temporizing measure often in the first 48-72 hours of hemoptysis, and daily flexible bronchoscopy should be performed to monitor for bleeding as well as the position of the blocker (73). Placement is often followed by the application of a more definitive therapeutic measure such as BAE. Once hemostasis has accomplished, every attempt should be made to deflate the balloon and allow for the bronchoscopic clearance of secretions and clots. Leaving the blocker in place for longer durations increases the risk of post-obstructive atelectasis, pneumonia, compression trauma and necrosis of the bronchial wall mucosa $(31,84)$.

Balloon tamponade can also be achieved by use of other catheters such as Fogarty catheters, which are inserted through the working channel of a flexible bronchoscope (65). 
These catheters cannot be left inside the airway, but offer effective tamponade if applied over the bleeding site.

PA catheter has been used in the past to manage massive hemoptysis. The advantage of using a PA catheter is that the smaller catheter can be deployed and inflated distally into smaller bronchi, thereby maintaining ventilation of the remainder of the lung (85). Additionally, the inflation pressure can be measured and altered according to the size and location of the bronchus where the PA catheter is deployed. In a case series of three patients (86), this technique was used to block segmental or subsegmental bronchi with an inflation pressure of 30-50 mmHg. The method was successful in controlling massive hemoptysis in all three cases within 48 hours. This technique is not routinely employed because often in massive hemoptysis, blockade of a larger airway is necessary when the bleeding distal airways cannot be identified. Other commercially available endobronchial blockers are available to block the proximal airways and are preferred over PA catheters (83).

\section{Rigid bronchoscopy}

Rigid bronchoscopy provides the advantage of establishing a safe and patent airway, that allows for isolation of the bleeding bronchus and maintain oxygenation and ventilation to the non-bleeding lung (87). Rigid bronchoscopy provides a large lumen for the passage of rigid suction, a large bore suction that allows clearance of obstructive clots under direct visualization (79). Compared to the therapeutic flexible bronchoscope, the large working channel of a rigid bronchoscope, can accommodate for a rigid suction catheter, a small soft suction catheter and a flexible bronchoscope for both suction and airway visualization, simultaneously. This efficient method of clot extraction, allows for timely resumption of ventilation and oxygenation, blockade of the hemorrhaging airway under direct vision and the use of intrabronchial therapeutic tools such as thermal techniques or application of ice-cold saline (73).

\section{Bronchoscopic interventions for bleeding control}

\section{Endobronchial medical therapy}

Multiple agents are used for endobronchial instillation in an attempt to obtain hemostasis, particularly when the source of bleeding is beyond the bronchoscope's reach $(88,89)$. Conlan et al. used ice-cold saline irrigation in
12 patients with massive hemoptysis defined as $>600 \mathrm{cc}$ of blood within 24 hours. In their study, irrigation with $4{ }^{\circ} \mathrm{C}$ normal saline in $50 \mathrm{cc}$ aliquots was performed using rigid bronchoscopy. Each patient underwent 300-750 cc of ice-cold saline lavage to the bleeding site. No other interventions were performed for massive hemoptysis management. Hemostasis was achieved in all 12 patients. Transient bradycardia during irrigation was noted in one patient, and two patients experienced recurrent hemoptysis in the same hospitalization. All patients were discharged from the hospital without additional intervention and three patients with bronchiectasis had follow up elective surgical resection (90). There were no controlled or comparison groups and the results of this study have not been verified in the literature (38).

Epinephrine and norepinephrine have been used in cases of massive hemoptysis, following TBLB to control bleeding (84), however the literature reports many different doses and dilutions of epinephrine, from 1:100,000 solution up to $20 \mathrm{~mL}$ of 1:20,000 solution (91-94). Cardiac arrhythmia is noted at doses as low as $0.1 \mathrm{mg}$ and although dilute doses are used in endobronchial application, caution must be exercised. Mall et al. reported the use of 1:1,000 epinephrine on 21 patients undergoing endobronchial biopsies in an average dose of $0.12 \mathrm{mg}$ of epinephrine injected endobronchially after the biopsy and no cardiac arrhythmias were noticed (95). Vaknin et al. studied the effect of endobronchial adrenalin on five dogs following the treatment with beta-blocker. They concluded that hypotension observed in dogs that were not treated with beta-blockers prior to endobronchial adrenalin application, was due to beta-adrenergic effect from the adrenalin (96). Steinfort et al. reported two cases of iatrogenic endobronchial bleeding following TBLB. A $5 \mathrm{~mL}$ aliquot of endobronchial epinephrine $(1: 20,000)$ was injected in both cases and an episode of narrow complex QRS tachycardia followed by ventricular fibrillation and hypotension was witnessed with elevated serum levels of epinephrine (97). Two ADH-derivatives (ornipressin and terlipressin) were used in cases of mild to moderate airway bleeding following TBLB in a retrospective study. Fifteen patients were identified in each group; it was noted that following terlipressin instillation, heart rate increased from $93 \pm 17$ to $101 \pm 22 \mathrm{bpm}(\mathrm{P}=0.03)$, and blood pressure decreased from $107 \pm 14$ to $101 \pm 17 \mathrm{mmHg}(\mathrm{P}=0.04)$. In contrast, ornipressin did not result in such adverse events (98). Tranexamic acid, a synthetic anti-fibrinolytic agent, used endobronchially to control bleeding induced by TBLB for the management of 
massive hemoptysis has been reported only in the form of case reports $(99,100)$.

Valipour et al. described a method of bronchoscopyguided topical hemostatic tamponade therapy (THT) in patients with life-threatening hemoptysis. THT was performed on patients with persistent endobronchial bleeding despite wedging, cold saline solution lavage, and regional instillation of epinephrine. The hemostatic agent used was oxidized regenerated cellulose (ORC), which is a sterile, knitted fabric, which swells into a gelatinous mass that aids in the formation of clot after it has been saturated with blood. THT was successfully performed in $98 \%$ of patients (56/57) with an immediate stop of hemoptysis. All 56 patients remained free of hemoptysis for the first $48 \mathrm{hr}$, however recurrent hemoptysis characterized as mild $(<30 \mathrm{~mL})$; or moderate $(30-100 \mathrm{~mL})$ developed in six patients $(10.5 \%)$ between 3 and 6 days after THT. Clinical signs and/or radiologic evidence of postobstructive pneumonia developed in five patients $(9 \%)$ within 6 days. Follow up bronchoscopic studies in 14 patients showed complete absorption of the material used for THT, and there was no histological evidence of foreign body tissue reaction (38).

Given the low risk profile reported with the use of iced normal saline, its availability and ease of use, we recommend use of endobronchial $4{ }^{\circ} \mathrm{C}$ normal saline, when available, to aid in accomplishing hemostasis. If epinephrine and norepinephrine is considered, the use of lower concentrations $(1: 100,000)$ in $2 \mathrm{~mL}$ aliquots, not exceeding maximum dose of $0.6 \mathrm{mg}$; close cardiac monitoring and limitation of use in patients with underlying coronary artery disease and cardiac arrhythmias is recommended (101). THT using ORC can be performed when other conservative strategies fail. It is noteworthy that in the setting of conservative management, the risk of recurrence is high and such measures are almost always complementary to a more definitive management method (8).

\section{Thermal ablative methods}

The use of endobronchial ablation, requires skills and expertise as well as equipment. In inexperienced hands, application of such methods of therapy can retract focus from more definitive modes of massive hemoptysis management. When used in the management of massive hemoptysis, thermal ablation is often applied in the setting of airway tumors, tumor debulking or other procedures that result in hemorrhage. These methods often accompany other methods of hemoptysis management. Close attention must be paid to the risk of airway fire if heat is used in the airway. Supplemental oxygen should be decreased to below $0.4 \mathrm{FiO}_{2}$ to prevent airway fire.

Laser therapy-Nd:YAG and Nd:YAP: light emitted by Nd:YAG laser is in the infrared spectrum. The energy from the laser beam is absorbed by tissues, and converted to heat, producing local effects such as photocoagulation, vaporization and necrosis. Laser therapy has been extensively used since the 1970s for management of airway tumors (102). Although still primarily used to debulk airway tumors, the photocoagulation effect of laser makes it attractive in the management of massive hemoptysis. One of the disadvantages of laser therapy is that it can only be used if bleeding originates from the airway wall/mucosa.

Dumon et al. demonstrated effective hemostasis in mild and moderate hemoptysis by photoresection and vaporization of underlying tumor using Neodymium: yttrium aluminum garnet (Nd:YAG) laser therapy (103). Encouraging evidence has been provided by Han $e t$ al. in their review of 110 patients who received $153 \mathrm{Nd}$ :YAG laser treatments for endobronchial tumors (104). Hemoptysis was present in 52 cases, and was successfully resolved in 40 $(77 \%)$ instances. Nine $(17 \%)$ cases had a reduction in the amount of hemoptysis, while the therapy was unsuccessful in three $(6 \%)$ cases. The study does not specify the severity of bleeding.

Electrocauterization-Argon Plasma Coagulation and Electrocautery: argon plasma photocoagulation (APC) is a non-contact method of inducing photocoagulation. This is achieved by using argon, an inert gas, to act as the medium for conduction of electricity. The electric current conducts through the inert gas and reaches target tissue. APC photocoagulation induces clot formation and is an effective way to control bleeding in massive hemoptysis originating from airway wall mucosa. Morice et al. analyzed the use of APC for indications of airway tumor debulking and hemoptysis in sixty patients (105). Thirty-one patients had hemoptysis alone and twenty-five patients had both tumor and hemoptysis as the indication for APC therapy. Six of these patients had hemoptysis $>200 \mathrm{~mL}$ per day. There was immediate resolution of hemoptysis in all patients, with no recurrence during a mean follow-up period of about three months.

Endobronchial electrocautery is an effective way to treat bronchial tumors. This technique uses direct electrical energy applied to tissue by contact. The tissue converts the electrical energy to heat, resulting in coagulation and 
necrosis. The availability of cautery blades and snares make this an effective method to debulk tumors $(73,106)$. Like the previous ablative methods discussed above and when the site of bleeding is identified and accessible to a contact probe, this technique may be used in the management of both massive and non-massive hemoptysis, after decreasing supplemental oxygen to less than $0.4 \mathrm{FiO}_{2}$.

\section{Treatment following localization and stabilization}

\section{Endovascular interventions: $B A E$}

First introduced in 1974, BAE is now widely used, often as first line therapy in the management of massive hemoptysis (107-109). Details of procedural technique in BAE are beyond the scope of this manuscript and should be reviewed elsewhere. Arteriogram is performed usually via a femoral artery cannulation. Active extravasation of contrast is seen in only $10-15 \%$ of all cases of hemoptysis. Lesions considered in lieu of active extravasation of contrast are bronchial arterial hypertrophy and tortuosity, hypervascularity, aneurysm formation, and arteriovenous malformations (107-109). Normal bronchial arterial appearance may be seen in up to $20 \%$ of cases. Embolotherapy of the offending bronchial artery is performed using one of many available studied agents. These include gelatin sponge, polyvinyl alcohol (PVA) particles, microspheres, liquid embolic agents such as n-butyl-2-cyanoacrylate, and metallic coil. Each agent has its own advantages and disadvantages, and the choice of agent depends on the operator's preference and institutional protocols (89).

The success rate of BAE ranges from $60 \%$ to $90 \%$ (107-109). In a study of 52 patients treated by BAE, Fruchter $\mathrm{et} \mathrm{al}$. reported an immediate success rate of $92 \%$ (48/52) within the first $24 \mathrm{hr} .45$ patients survived beyond $24 \mathrm{hr}$ and recurrent bleeding did not occur in 19 (42.2\%) during a median follow-up period of 60 months (range, 6-130 months). Bleeding recurred in 26 (57.7\%); within 30 days in $15(33.3 \%)$ and after 1 month in the other 11 (24.4\%). The average time to onset of early and late repeat bleeding was 2 and 506 days, respectively. Idiopathic bronchiectasis and lung cancer were associated with a high likelihood of late bleeding recurrence (109). Rebleeding can occur depending on the etiology of the bleed and may warrant repeat BAE (110). Recurrence is particularly noted in diseases such as $\mathrm{TB}$, bronchiectasis, aspergilloma and bronchogenic carcinoma (111-113).
Complications of BAE include self-limiting chest pain, self-limiting dysphagia from non-target embolization to the esophagus, and transverse myelitis from non-target embolization to the spinal artery (114). Rare complications include cortical blindness, tracheoesophageal fistula from esophageal ischemia, bronchial stenosis and necrosis from bronchial wall ischemia, ischemic colitis, and pulmonary infarction (28).

\section{Surgical interventions}

The role of surgery in massive hemoptysis is reduced over time and reserved mainly if one or more of the above mentioned approaches fail, or is only temporarily successful. Surgery remains the procedure of choice in the management of massive hemoptysis secondary to iatrogenic PA rupture, chest trauma and aspergilloma resistant to other therapeutic options $(115,116)$. Andréjak et al. have reported a series of 111 (13.6\%) lung resections for severe hemoptysis. They categorized resections into three groups as emergency, scheduled (after bleeding control) and planned (after discharge). Mortality ratios were $35 \%, 4 \%$ and $0 \%$ among the groups, respectively. They recommended avoiding emergency resections when possible and utilizing nonsurgical approaches to obtain hemostasis and optimize presurgical condition prior to any resection to minimize the morbidity and mortality (117). Garzon et al. reported their 15 years' experience of 74 resections in the management of massive hemoptysis, defined as $600 \mathrm{~mL} / 24$ hours, and showed a mortality rate of $13 \%$. They reported an overall survival rate of $75 \%(10,25,118)$.

In a retrospective analysis of 120 patients in South Africa, Knott-Craig and colleagues noted that $36.4 \%$ of all patients who were admitted to the hospital for massive hemoptysis and were managed by non-surgical means, were readmitted within 6 months follow up period and $45 \%$ of these recurrences resulted in mortality (16). Pulmonary TB was the underlying etiology of hemoptysis in $85 \%$ of the patients and overall hospital mortality was 10\% (12/120) and was similar for those having pulmonary resection $(7.1 \%$, $3 / 42$ ), and those who were managed with non-surgical means $(11.5 \%, 9 / 78)$.

Surgery is particularly relevant in conditions such as TB, fungal infections such as aspergilloma, and where massive hemoptysis originates from pulmonary vasculature (i.e., Rasmussen aneurysm-chronic inflammation in the setting of TB leading to aneurysmal dilatation of a PA branch) $(64,119)$. Factors associated with adverse surgical outcomes 


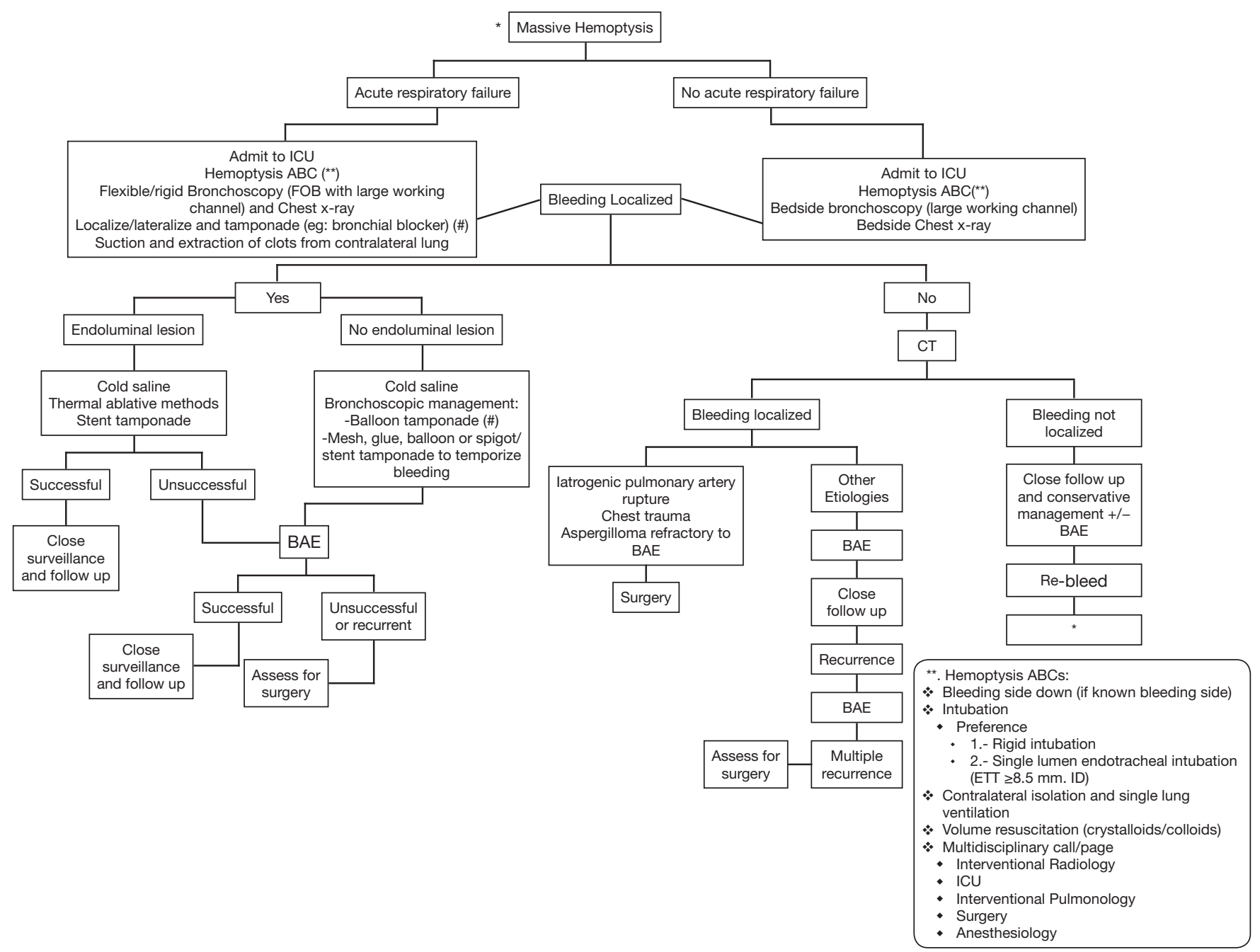

Figure 3 Flowchart for a systematic approach to the management of massive hemoptysis. \#, paralysis may be required to maintain balloon position, as well as prevent cough until definitive management (BAE/surgery) is performed; *, start from the top of the flowchart; **, see hemoptysis ABCs. BAE, bronchial artery embolization.

include advanced age, pneumonectomy, pleural adhesions, bronchiectasis and broncholithiasis (8).

\section{Conclusions}

Airway management in the setting of massive hemoptysis is often dealt with under urgent/emergent situations. When managing massive hemoptysis, a systematic approach is key to timely control and reversal of potentially fatal complications (Figure 3). Preparedness and prevention prior to endobronchial procedures, careful review of patients risk factors and procedure indication are essential.
Ideally, management approaches listed above, need to be rehearsed in advance during simulation session as a team. A multidisciplinary team approach (pulmonology, interventional pulmonology, interventional radiology and surgery) should be undertaken as soon as the condition is identified. When managing massive hemoptysis, time is alveoli!

\section{Acknowledgements}

The authors would like to thank Trinidad Sanchez, MD, for her work on figures and data collection. 


\section{Footnote}

Conflicts of Interest: The authors have no conflicts of interest to declare.

\section{References}

1. Ryan TC, Lineberry WT Jr. Pneumonectomy for pulmonary hemorrhage in tuberculosis. Am Rev Tuberc 1950;61:426-30.

2. Ross CA. Emergency pulmonary resection for massive hemoptysis in tuberculosis. J Thorac Surg 1953;26:435-9.

3. Ehrenhaft JL, Taber RE. Management of massive hemoptysis, not due to pulmonary tuberculosis or neoplasm. J Thorac Surg 1955;30:275-84.

4. Johnson JF. Changes in plasma prothrombin, Ac-globulin, and antithrombin concentration following intravenous administration of estrogens. Proc Soc Exp Biol Med 1957;94:92-4.

5. Rémy J, Voisin C, Dupuis C, et al. Traitement des hémoptysies par embolisation de la circulation systémique. Ann Radiol (Paris) 1974;17:5-16.

6. Dweik RA, Stoller JK. Role of bronchoscopy in massive hemoptysis. Clin Chest Med 1999;20:89-105.

7. Stoller JK. Diagnosis and management of massive hemoptysis. A review. Respir Care 1992;37:564-81.

8. Corey R, Hla KM. Major and massive hemoptysis: reassessment of conservative management. Am J Med Sci 1987;294:301-9.

9. Crocco JA, Rooney JJ, Fankushen DS, et al. Massive hemoptysis. Arch Intern Med 1968;121:495-8.

10. Garzon AA, Gourin A. Surgical management of massive hemoptysis: a ten-year experience. Ann Surg 1978;187:267-71.

11. Hirshberg B, Biran I, Glazer M, et al. Hemoptysis: etiology, evaluation, and outcome in a tertiary referral hospital. Chest 1997;112:440-4.

12. Johnston H, Reisz G. Changing spectrum of hemoptysis. Underlying causes in 148 patients undergoing diagnostic flexible fiberoptic bronchoscopy. Arch Intern Med 1989;149:1666-8.

13. Reisz G, Stevens D, Boutwell C, et al. The causes of hemoptysis revisited. A review of the etiologies of hemoptysis between 1986 and 1995. Missouri Medicine 1997;94:633-5.

14. Kvale PA, Selecky PA, Prakash UB, et al. Palliative care in lung cancer: ACCP evidence-based clinical practice guidelines (2nd edition). Chest 2007;132:368S-403S.
15. Flume PA, Yankaskas JR, Ebeling M, et al. Massive hemoptysis in cystic fibrosis. Chest 2005;128:729-38.

16. Knott-Craig CJ, Oostuizen G, Rossouw G, et al. Management and prognosis of massive hemoptysis: recent experience with 120 patients. J Thorac Cardiovasc Surg 1993;105:394-7.

17. Mal H, Rullon I, Mellot F, et al. Immediate and long-term results of bronchial artery embolization for life-threatening hemoptysis. Chest 1999;115:996-1001.

18. Ong TH, Eng P. Massive hemoptysis requiring intensive care. Intensive Care Med 2003; 29:317-20.

19. Fartoukh M, Khoshnood B, Parrot A, et al. Early prediction of in-hospital mortality of patients with hemoptysis: an approach to defining severe hemoptysis. Respiration 2012;83:106-14.

20. Lee TW, Wan S, Choy DK, et al. Management of massive hemoptysis: a single institution experience. Ann Thorac Cardiovasc Surg 2000;6:232-5.

21. Amirana M, Frater R, Tirschwell P, et al. An aggressive surgical approach to significant hemoptysis in patients with pulmonary tuberculosis. Am Rev Respir Dis 1968;97:187-92.

22. Bobrowitz ID, Ramakrishna S, Shim YS. Comparison of medical vs. surgical treatment of major hemoptysis. Arch Intern Med 1983;143:1343-46.

23. Ibrahim WH. Massive haemoptysis: the definition should be revised. Eur Respir J 2008;32:1131.

24. Holsclaw DS, Grand RJ, Scwachman H. Massive hemoptysis in cystic fibrosis. J Pediatr 1970;76:829-38.

25. Garzon AA, Cerruti MM, Golding ME. Exsanguinating hemoptysis. J Thorac Cardiovasc Surg 1982;84:829-33.

26. Khalil A, Soussan M, Mangiapan G, et al. Utility of highresolution chest CT scan in the emergency management of haemoptysis in the intensive care unit: severity, localization and aetiology. Br J Radiol 2007;80:21-5.

27. Cahill BC, Ingbar DH. Massive hemoptysis. Assessment and management. Clin Chest Med 1994;15:147-67.

28. Deffebach ME, Charan NB, Lakshminarayan S, et al. The bronchial circulation: small, but a vital attribute to the lung. Am Rev Respir Dis 1987;135:463-81.

29. Remy J, Remy-Jardin M, Voisin C. Endovascular management of bronchial bleeding. In: Butler J. editor. The Bronchial Circulation. New York: Dekker, 1992:667-723.

30. Khalil A, Parrot A, Nedelcu C, et al. Severe hemoptysis of pulmonary arterial origin: Signs and role of multidetector row CT. Chest 2008;133:212-9.

31. Sakr L, Dutau H. Massive hemoptysis: an update on the role of bronchoscopy in diagnosis and management. 
Respiration 2010;80:38-58.

32. Roberts AC. Bronchial artery embolization therapy. J Thorac Imaging 1990;5:60-72.

33. Uflacker R, Kaemmerer A, Picon PD, et al. Bronchial artery embolization in the management of hemoptysis: Technical aspects and long-term results. Radiology 1985;157:637-44.

34. Cauldwell EW, Sickert RG, Lininger RE, et al. The bronchial arteries: an anatomic study of 150 human cadavers. Surg Gynecol Obstet 1948;86:395-412.

35. Seitz AE, Olivier KN, Adjemian J, et al. Trends in bronchiectasis among medicare beneficiaries in the United States, 2000 to 2007. Chest 2012;142:432.

36. Quint JK, Millett ER, Joshi M, et al. Changes in the incidence, prevalence and mortality of bronchiectasis in the UK from 2004 to 2013: a population-based cohort study. Eur Respir J 2016;47:186.

37. Shigemura N, Wan IY, Yu SC, et al. Multidisciplinary management of life-threatening massive hemoptysis: a 10year experience. Ann Thorac Surg 2009;87:849-53.

38. Valipour A, Kreuzer A, Koller H, et al. Bronchoscopyguided topical hemostatic tamponade therapy for the management of life-threatening hemoptysis. Chest 2005;127:2113-18.

39. Fartoukh M, Khalil A, Louis L, et al. An integrated approach to diagnosis and management of severe haemoptysis in patients admitted to the intensive care unit: a case series from a referral centre. Respir Res 2007;8:11.

40. Hsiao EI, Kirsch CM, Kagawa FT, et al. Utility of fiberoptic bronchoscopy before bronchial artery embolization for massive hemoptysis. AJR Am J Roentgenol 2001;177:861-7.

41. Revel MP, Fournier LS, Hennebicque AS, et al. Can CT replace bronchoscopy in the detection of the site and cause of bleeding in patients with large or massive hemoptysis? AJR Am J Roentgenol 2002;179:1217-24.

42. Gourin A, Garzon AA. Operative treatment of massive hemoptysis. Ann Thorac Surg 1974;18:52-60.

43. McCollun WB, Mattox KL, Guin LN, et al. Immediate operative treatment for massive hemoptysis. Chest 1975;67:152-5.

44. Yang CT, Berger HW. Conservative management of lifethreatening hemoptysis. Mt Sinai J Med 1978;45:329-33.

45. Conlan AA, Hurwitz SS, Krige L, et al. Massive hemoptysis: Review of 123 cases. J Thorac Cardiovasc Surg 1983;85:120-4.

46. Tanaka N, Yamakado K, Murashima S, et al. Superselective bronchial artery embolization for hemoptysis with a coaxial microcatheter system. J Vasc Interv Radiol 1997;8:65-70.

47. Zhang Y, Chen C, Jiang GN. Surgery of massive hemoptysis in pulmonary tuberculosis: immediate and long-term outcomes. J Thorac Cardiovasc Surg 2014;148:651-6.

48. Rasmussen, V. On haemoptysis, especially when fatal, in its anatomical and clinical aspects. Edinburgh Med J 1968;14:385.

49. J. Zatakia, S. Shojaee. Calcified Lymph node: an Uncommon Cause of Hemoptysis. Ann Am Thorac Soc 2015;12:1240-2.

50. Miller RR, McGregor DH. Hemorrhage from carcinoma of the lung. Cancer 1980;46:200.

51. Boulay F, Berthier F, Sisteron O, et al. Seasonal variation in cryptogenic and noncryptogenic hemoptysis hospitalizations in France. Chest 2000;118:440-4.

52. Herth F, Ernst A, Becker HD. Long-term outcome and lung cancer incidence in patients with hemoptysis of unknown origin. Chest 2001;120:1592-4.

53. Haponik EF, Britt EJ, Smith PL, et al. Computed chest tomography in the evaluation of hemoptysis: impact on diagnosis and treatment. Chest 1987;91:80-5.

54. Millar AB, Boothroyd AE, Edwards D, et al. The role of computed tomography (CT) in the investigation of unexplained haemoptysis. Respir Med 1992;86:39-44.

55. Set PA, Flower CD, Smith IE, et al. Hemoptysis: comparative study of the role of CT and fiberoptic bronchoscopy. Radiology 1993;189:677-80.

56. Naidich DP, Funt S, Ettenger NA, et al. Hemoptysis: CT- bronchoscopic correlations in 58 cases. Radiology 1990;177:357-62.

57. Yoon YC, Lee KS, Jeong YJ, et al. Hemoptysis: bronchial and nonbronchial systemic arteries at 16-detector row CT. Radiology 2005;234:292-8.

58. Remy-Jardin M, Bouaziz N, Dumont P, et al. Bronchial and nonbronchial systemic arteries at multi-detector row CT angiography: comparison with conventional angiography. Radiology 2004;233:741-9.

59. Yoon W, Kim YH, Kim JK, et al. Massive hemoptysis: prediction of nonbronchial systemic arterial supply with chest CT. Radiology 2003;227:232-8.

60. Osaki S, Nakanishi Y, Wataya H, et al. Prognosis of bronchial artery embolization in the management of hemoptysis. Respiration 2000;67:412-6.

61. van den Heuvel MM, Els Z, Koegelenberg CF. Risk factors for recurrence of haemoptysis following bronchial artery embolisation for life-threatening haemoptysis. Int J Tuberc Lung Dis 2007;11:909-14. 
62. Wang GR, Ensor JE, Gupta S, et al. Bronchial artery embolization for the management of hemoptysis in oncology patients: utility and prognostic factors. J Vasc Interv Radiol 2009;20:722-9.

63. Razazi K, Parrot A, Khalil A, et al. Severe haemoptysis in patients with nonsmall cell lung carcinoma. Eur Respir J 2015;45:756.

64. Jean-Baptiste E. Clinical assessment and management of massive hemoptysis. Crit Care Med 2000;28:1642-7.

65. Solomonov A, Fruchter O, Zuckerman T, et al. Pulmonary hemorrhage: A novel mode of therapy. Respir Med 2009;103:1196-200.

66. Wahidi MM, Rocha AT, Hollingsworth JW, et al. Contraindications and safety of transbronchial lung biopsy via flexible bronchoscopy. A survey of pulmonologists and review of the literature. Respiration 2005;72:285-95.

67. Rebulla P. Platelet transfusion trigger in difficult patients. Transfus Clin Biol 2001;8:249-54.

68. Zavala DC. Pulmonary hemorrhage in fiberoptic transbronchial biopsy. Chest 1976;70:584-8.

69. Papin TA, Lynch JP, III, Weg JG. Transbronchial biopsy in the thrombocytopenic patient. Chest 1985;88:549-52.

70. Dransfield MT, Garver RI, Weill D. Standardized guidelines for surveillance bronchoscopy reduce complications in lung transplant recipients. J Heart Lung Transplant 2004;23:110-4.

71. Herth FJ, Becker HD, Ernst A. Aspirin does not increase bleeding complications after transbronchial biopsy. Chest 2002;122:1461-4.

72. Ernst A, Eberhardt R, Wahidi M, et al. Effect of Routine Clopidogrel Use on Bleeding Complications After Transbronchial Biopsy in Humans. Chest 2006;129:734-7.

73. Colchen A, Fischler M. Emergency interventional bronchoscopies. Rev Pneumol Clin 2011;67:209-13.

74. Santana-Cabrera L, Arroyo MF, Rodriguez AU, et al. Double-lumen endobronchial tube in the emergency management of massive hemoptysis. J Emerg Trauma Shock 2010;3:305.

75. McCalley SW. Clinical efficacy of early and delayed fiberoptic bronchoscopy in patients with hemoptysis. Am Rev Respir Dis 1982;125:269-70.

76. Gong H, Salvatierra C. Clinical efficacy of early and delayed fiberoptic bronchoscopy in patients with hemoptysis. Am Rev Respir Dis 1981;124: 221-5.

77. Karmy-Jones R, Cuschieri J, Vallières E. Role of bronchoscopy in massive hemoptysis. Chest Surg Clin N Am 2001;11:873-906.

78. Cordasco EM Jr, Mehta AC, Ahmad M. Bronchoscopically induced bleeding. A summary of nine years' Cleveland clinic experience and review of the literature. Chest 1991;100:1141-7.

79. Hassine E, Marniche K, Bousnina S, et al. Management of massive hemoptysis: current role of interventional endoscopy. Tunis Med 2003;81:94-100.

80. Reisz G. Topical hemostatic tamponade: another tool in the treatment of massive hemoptysis. Chest 2005;127:1888-9.

81. Dutau H, Palot A, Haas A, et al. Endobronchial embolization with a silicone spigot as a temporary treatment for massive hemoptysis: a new bronchoscopic approach of the disease. Respiration 2006;73:830-2.

82. Hiebert CA. Balloon catheter control of life-threatening hemoptysis. Chest 1974;66:308-9.

83. Mourisse J, Lerou J. Searching for the ideal endobronchial blocker. Anesthesiology 2013;119:990.

84. Alraiyes AH, Alraies MC, Machuzak MS. Q: Does massive hemoptysis always merit diagnostic bronchoscopy? Cleve Clin J Med 2014;81:662-4.

85. Jolliet P, Soccal P, Chevrolet JC. Control of massive hemoptysis by endobronchial tamponade with a pulmonary artery balloon catheter. Crit Care Med 1992;20:1730-2.

86. Jeon K, Kim H, Yu CM, et al. Rigid bronchoscopic intervention in patients with respiratory failure caused by malignant central airway obstruction. J Thorac Oncol 2006;1:319-23.

87. Alraiyes AH, Machuzak MS. Rigid bronchoscopy. Semin Respir Crit Care Med 2014;35:671-80.

88. Tsukamoto T, Sasaki H, Nakamura H. Treatment of hemoptysis patients by thrombin and fibrinogen-thrombin infusion therapy using a fiberoptic bronchoscope. Chest 1989;96:473-6.

89. Prutsky G, Domecq JP, Salazar CA, et al. Antifibrinolytic therapy to reduce haemoptysis from any cause. Cochrane Database Syst Rev 2012;4:CD008711.

90. Conlan AA, Hurwitz SS. Management of massive haemoptysis with the rigid bronchoscope and cold saline lavage. Thorax 1980;35:901-4.

91. British Thoracic Society Bronchoscopy Guidelines Committee, a Subcommittee of Standards of Care Committee of British Thoracic Society. British Thoracic Society guidelines on diagnostic flexible bronchoscopy. Thorax 2001;56 Suppl 1:11-21.

92. Lee P, Mehta AC, Mathur PN. Management of complications from diagnostic and interventional Bronchoscopy. Respirology 2009;14:940-53.

93. Ernst A. Introduction to bronchoscopy. New York: 
Cambridge University Press, 2009:105.

94. Parkash UB. Bronchoscopy. Philadelphia: LippincottRaven, 1994:238.

95. Mall W, Abel H. Topical application of epinephrine during bronchoscopy in barbiturate-halothane-anaesthesia and its influence on cardiac action. Bronchopneumologie 1978;28:311-6.

96. Vaknin Z, Manisterski Y, Ben-Abraham R. Is endotracheal adrenaline deleterious because of the beta ad-renergic effect? Anesth Analg 2001;92:1408-12.

97. Steinfort DP, Herth FJ, Eberhardt R. Potentially fatal arrhythmia complicating endobronchial epinephrine for control of iatrogenic bleeding. Am J Respir Crit Care Med 2012;185:1028-30.

98. Tüller C, Tüller D, Tamm M, et al. Hemodynamic effects of endobronchial application of ornipressin versus terlipressin. Respiration 2004;71:397-401.

99. Hurley M, Bhatt J, Smyth A. Treatment massive haemoptysis in cystic fibrosis with tranexamic acid. J R Soc Med 2011;104 Suppl 1:S49-52.

100.Zamani A. Bronchoscopic intratumoral injection of tranexamic acid: a new technique for control of biopsyinduced bleeding. Blood Coagul Fibrinolysis 2011;22:440-2.

101. Khoo KL, Lee P, Mehta AC. Endobronchial epinephrine: confusion is in the air. Am J Respir Crit Care Med 2013;187:1137-8.

102. Kvale PA, Eichenhorn MS, Radke JR, et al. YAG laser photoresection of lesions obstructing the central airways. Chest 1985;87:283-8.

103. Dumon JF, Shapshay S, Bourcereau J, et al. Principles for safety in application of neodymium-YAG laser in bronchology. Chest 1984;86:163-8.

104.Han CC, Prasetyo D, Wright GM. Endobronchial palliation using $\mathrm{Nd}$ : YAG laser is associated with improved survival when combined with multimodal adjuvant treatments. J Thorac Oncol 2007;2:59-64.

105. Morice RC, Ece T, Ece F, et al. Endobronchial argon plasma coagulation for treatment of hemoptysis and neoplastic airway obstruction. Chest 2001;119:781-7.

106. Sheski FD, Mathur PN. Cryotherapy, electrocautery, and brachytherapy. Clin Chest Med 1999;20:123-38.

107.Fruchter O, Schneer S, Rusanov V, et al. Bronchial artery embolization for massive hemoptysis: long-term followup. Asian Cardiovasc Thorac Ann 2015;23:55-60.

108. Chen J, Chen LA, Liang ZX, et al. Immediate and long-term results of bronchial artery embolization for hemoptysis due to benign versus malignant pulmonary diseases. Am J Med Sci 2014;348:204-9.

109.Fernando HC, Stein M, Benfield JR, et al. Role of bronchial artery embolization in the management of hemoptysis. Arch Surg 1998;133:862-6.

110. Garcia-Olivé I, Sanz-Santos J, Centeno C, et al. Predictors of recanalization in patients with life-threatening hemoptysis requiring artery embolization. Arch Bronconeumol 2014;50:51-6.

111. Xu W, Wang HH, Bai B. Emergency transcatheter arterial embolization for massive hemoptysis due to pulmonary tuberculosis and tuberculosis sequelae. Cell Biochem Biophys 2015;71:179-87.

112. Anuradha C, Shyamkumar NK, Vinu M, et al. Outcomes of bronchial artery embolization for life-threatening hemoptysis due to tuberculosis and post-tuberculosis sequelae. Diagn Interv Radiol 2012;18:96-101.

113. Chun JY, Morgan R, Belli AM. Radiological management of hemoptysis: a comprehensive review of diagnostic imaging and bronchial arterial embolization. Cardiovasc Intervent Radiol 2010;33:240-50.

114. Sharma M, Garg M, Ghuman MS. Bronchial artery embolization in chronic pulmonary thromboembolism: A therapeutic dilemma. Lung India 2015;32:624-6.

115. Nakajima T, Yoshino I. Massive Hemoptysis; Clinical Approach and Surgical Treatment. Kyobu Geka 2015;68:665-70.

116. Kiral H, Evman S, Tezel C, et al. Pulmonary Resection in the Treatment of Life-Threatening Hemoptysis. Ann Thorac Cardiovasc Surg 2015;21:125-31.

117.Andréjak C, Parrot A, Bazelly B, et al. Surgical lung resection for severe hemoptysis. Ann Thorac Surg 2009;88:1556-65.

118. Garzon AA, Cerruti M, Gourin A, et al. Pulmonary resection for massive hemoptysis. Surgery 1970;67:633-8.

119. Sakai M, Ozawa Y, Nakajima T, et al. Thick lung wedge resection for acute life-threatening massive hemoptysis due to aortobronchial fistula. J Thorac Dis 2016;8:E957-60.
Cite this article as: Radchenko C, Alraiyes AH, Shojaee S. A systematic approach to the management of massive hemoptysis. J Thorac Dis 2017;9(Suppl 10):S1069-S1086. doi: 10.21037/ jtd.2017.06.41 